\title{
SEGURANÇA, SAÚDE E ERGONOMIA DE TRABALHADORES EM GALPÕES DE FRANGOS DE CORTE EQUIPADOS COM DIFERENTES SISTEMAS DE ABASTECIMENTO DE RAÇÃO'
}

\author{
CINARA DA C. S. CARVALHO ${ }^{2}$, CECÍLIA DE F. SOUZA ${ }^{3}$, ILDA DE F. F. TINÔCO ${ }^{4}$, \\ MARIA DE F. A. VIEIRA ${ }^{5}$, LUCIANO J. MINETTE ${ }^{6}$
}

\begin{abstract}
RESUMO: O abastecimento de ração nos galpões avícolas pode ser feito de forma manual ou automática, e por demandar esforço acredita-se que o abastecimento manual pode expor o tratador a sobrecarga física. Desta forma, o objetivo deste trabalho foi avaliar os fatores ergonômicos, a postura adotada para a realização das atividades de manejo, bem como a influência na biomecânica dos trabalhadores atuantes em galpões avícolas equipados com comedouro tubular ou automático. Os fatores ergonômicos analisados foram: carga física de trabalho, ambiente térmico, análise postural e biomecânica. Verificou-se que, nos galpões onde o sistema de abastecimento de ração era tubular, os trabalhadores estiveram expostos a maior esforço físico. Baseado no ambiente térmico, o manejo foi considerado pesado para os dois sistemas de abastecimento. As posturas adotadas na maioria das atividades merecem ações corretivas imediatas. $\mathrm{O}$ manejo nos galpões equipados com comedouro tubular expõe os trabalhadores a risco de lesão no ombro, cotovelo, dorso, coxofemoral, joelho e tornozelo. Desta forma, pode-se concluir que o manejo em galpões avícolas equipados com comedouro tubular pode ser considerado prejudicial para o tratador, expondo-o a riscos de lesão no corpo.
\end{abstract}

PALAVRAS-CHAVE: avicultura, comedouro, ergonomia.

\section{SAFETY, HEALTH AND ERGONOMICS OF WORKERS IN POULTRY HOUSES SYSTEMS EQUIPPED WITH DIFFERENT FEED SUPPLY}

\begin{abstract}
The feed supply in poultry houses can be done manually or automatically, to require effort is believed that manual supply could expose the attendant to physical overload. Thus, the objective of this study was to evaluate the ergonomic factors, and effect on posture and biomechanics of workers in poultry houses equipped with manual or automatic feeder. The analyzed factors were: physical work load, thermal environment, noise, lighting, postural analysis and biomechanics. It was found that in the sheds where the food supply system was manual, workers were exposed to greater physical effort. Based on the thermal environment management it was considered heavy for the two supply systems. The postures used in most activities deserve immediate corrective action. The handling in sheds equipped with manual feeder exposes workers to risk of injury in the shoulder, elbow, back, hip, knee and ankle. Thus, it can be concluded that management in poultry facilities equipped with manual feeder can be considered detrimental to the attendant exposing him to health risks and body damage.
\end{abstract}

KEYWORDS: aviculture, feed troughs, ergonomics.

\footnotetext{
${ }^{1}$ Extraído da Tese de Doutorado do primeiro autor. Projeto financiado pela FAPEMIG

${ }^{2}$ Eng ${ }^{a}$ Agrícola, Profa. Doutora, Departamento de Ciências Agrárias, UNIMONTES, Janaúba - MG, Fone: (0XX38) 3821.2756, cínara.carvalho@unimontes.br

${ }^{3}$ Eng $^{\mathrm{a}}$ Agrícola, Profa. Doutora, Departamento de Engenharia Agrícola, UFV, Viçosa - MG.

${ }_{5}^{4}$ Eng ${ }^{\underline{a}}$ Agrícola, Profa. Doutora, Departamento de Engenharia Agrícola, UFV, Viçosa - MG.

${ }^{5}$ Zootecnista, Mestranda em Engenharia Agrícola, Departamento de Engenharia Agrícola, UFV, Viçosa - MG.

${ }^{6}$ Engenheiro Florestal, Prof. Doutor, Departamento de Engenharia Elétrica e de Produção, UFV, Viçosa - MG.

Recebido pelo Conselho Editorial em: 23-9-2010

Aprovado pelo Conselho Editorial em: 22-3-2011
} 


\section{INTRODUÇÃO}

Os volumes de produção e exportação atingidos nos últimos anos destacaram a avicultura brasileira, tanto pela geração de renda ao meio rural, quanto pela oferta à população de uma proteína de alta qualidade e sanidade (MENEGALI et al., 2009).

Contudo, percebe-se ainda que diversos aspectos da produção de frangos de corte precisam ser melhorados, para que todos os segmentos envolvidos sejam devidamente beneficiados, e essa condição é nítida, principalmente no que tange às questões relativas à saúde e segurança dos trabalhadores (AMARAL, 2007).

Durante a fase de criação de frangos de corte, sabe-se que o ambiente interno onde os frangos e os trabalhadores estão inseridos é composto por fatores físicos, químicos e biológicos, que incluem o ambiente aéreo, luz, ruído e componentes construtivos. Em alguns casos, devido ao sistema de manejo adotado, estes componentes podem atingir níveis prejudiciais, sendo, então, considerados como os principais fatores de risco para a saúde dos tratadores (TINÔCO, 2001; MIRAGLIOTTA et al., 2006; NÄ̈̈S et al., 2007; MENEGALI et al., 2009; VIGODERIS et al., 2010). Além disso, durante o manejo de um galpão, os trabalhadores podem executar atividades que demandam força e geram posturas inadequadas. De acordo com COUTO (2007), posturas desfavoráveis provocam um aumento de fadiga no trabalhador e levam, ao longo do tempo, a lesões graves.

Associado ao estudo da análise de postura, DUL \& WEERDMEESTER (1995) sugerem a análise de biomecânica para estimar as tensões que ocorrem nos músculos e articulações durante uma postura ou um movimento, principalmente quando a atividade em questão requer demasiado esforço físico.

Contudo, a Ergonomia tem evoluído muito nas últimas décadas, trazendo inúmeras contribuições para o setor urbano, entretanto ainda são poucas as contribuições para o setor rural (ALENCAR et al., 2006; MINETTE et al., 2007). Contudo, percebe-se que os problemas relacionados a acidentes e doenças do trabalho podem ser minimizados a partir da implantação de um programa de ergonomia e adequação das atividades de acordo com as normas de segurança no trabalho, impostas pelo Ministério do Trabalho e Emprego.

Dentro deste contexto de melhorias, verifica-se que, atualmente, os novos galpões de frangos de corte instalados no Brasil são dotados de sistemas de abastecimento de ração automáticos, que têm como objetivo melhorar o processo de distribuição de ração de forma uniforme, reduzir o desperdício e minimizar o esforço feito pelos tratadores. No entanto, existem ainda galpões antigos equipados com comedouros manuais ou tubulares que demandam maior tempo para $o$ preenchimento total e que exigem grande esforço por parte dos trabalhadores, que necessitam, num período rápido, abastecer todos os comedouros a partir do uso de baldes e tração de diversos carrinhos de mão cheios de ração que chegam a pesar até $200 \mathrm{~kg}$.

Partindo do pressuposto de que o serviço realizado em galpões equipados com comedouros manuais exige maior esforço físico dos trabalhadores e que os mesmos podem estar sujeitos a problemas de saúde, quando comparado com os tratadores que desempenham o manejo em galpões dotados de sistema de abastecimento automático, este trabalho teve como objetivo comparar os fatores ergonômicos, o efeito na postura e as tensões nos músculos e articulações dos trabalhadores atuantes em galpões de frangos de corte equipados com comedouro tubular ou comedouro automático, a partir dos valores estabelecidos pelas leis propostas pelas Normas Regulamentadoras do Ministério do Trabalho e Emprego.

\section{MATERIAL E MÉTODOS}

O trabalho foi realizado em galpões avícolas, pertencentes ao sistema de integração de empresa comercial, representativa de grande parte da avicultura industrial do Brasil. 
Foram avaliadas as condições de trabalho de 14 funcionários pertencentes aos galpões comerciais, equipados com comedouro manual e galpões com comedouro automatizado. Os sistemas de abastecimento de ração comparados foram: comedouro automático e tipo tubular.

A carga física de trabalho ou carga cardiovascular (CCV) foi coletada por meio de um medidor de frequência cardíaca da marca polar eletro, com taxa de amostragem a cada 5 segundos. $\mathrm{O}$ equipamento era composto por um receptor digital, uma fita elástica e um transmissor de sensores, colocados na altura do peito. O polar era colocado nos trabalhadores no início da jornada, às $7 \mathrm{~h}$, e retirado no final do expediente, às $17 \mathrm{~h}$, permanecendo inclusive durante as pausas para higiene, almoço e descanso.

Utilizando os dados coletados, foi determinada a carga física de trabalho em cada atividade e a carga de trabalho cardiovascular no trabalho, a partir da metodologia proposta por APUD (1989).

Para o cálculo da carga cardiovascular, foi utilizada a eq.(1):

$\mathrm{CCV}=[(\mathrm{FCT}-\mathrm{FCR}) /(\mathrm{FCM}-\mathrm{FCR})] 100$

em que,

CCV - carga cardiovascular, \%;

FCT - frequência cardíaca de trabalho, bpm;

FCR - frequência cardíaca de repouso, bpm, e

FCM - frequência cardíaca máxima (220 - idade).

A frequência cardíaca limite (FCL) em bpm, para a carga cardiovascular de $40 \%$, foi obtida pela seguinte, proposta por APUD (1989):

$\mathrm{FCL}=0,40 \times(\mathrm{FCM}-\mathrm{FCR})+\mathrm{FCR}$

A carga física de trabalho foi classificada de acordo com a frequência cardíaca de trabalho (Tabela 1).

TABELA 1. Classificação da carga física de trabalho através da frequência cardíaca de trabalho. Classification of physical work load through the heart work.

\begin{tabular}{cc}
\hline Carga Física de Trabalho & Frequência Cardíaca em bpm \\
\hline Muito leve & $<75$ \\
Leve & $75-100$ \\
Moderadamente pesada & $100-125$ \\
Pesada & $125-150$ \\
Pesadíssima & $150-175$ \\
Extremamente pesada & $>175$ \\
\hline
\end{tabular}

Para a coleta de dados do ambiente térmico, foi utilizado um termômetro digital de IBUTG (Índice de Bulbo Úmido e Termômetro de Globo) da marca Wibget, modelo RSS-214. O aparelho foi posicionado no centro geométrico da cada galpão, na altura correspondente à média do tórax dos trabalhadores e programado para registrar as temperaturas de bulbo seco, bulbo úmido e globo negro.

O IBUTG foi calculado por meio da equação descrita a seguir, adequado para avaliação de ambientes internos (sem carga solar), de acordo com o estabelecido pela NR 15, anexo $\mathrm{n}^{\circ} 3$ (2008):

$\mathrm{IBUTG}=0,7 \mathrm{tbn}+0,3 \mathrm{tg}$

em que,

tbn - temperatura de bulbo úmido natural, ${ }^{\circ} \mathrm{C}, \mathrm{e}$

tg - temperatura de globo, ${ }^{\circ} \mathrm{C}$. 
Os valores de IBUTG obtidos foram confrontados com aqueles considerados como limites tolerantes, obtidos na Tabela 3, por intermédio da Tabela 2.

TABELA 2. Taxas de metabolismo por tipo de atividade. Metabolism rates by activity type.

\begin{tabular}{lc}
\hline Tipo de Atividade & $\mathrm{kcal} \mathrm{h}^{-1}$ \\
\hline Sentado em repouso & 100 \\
\hline Trabalho leve & 125 \\
Sentado, movimentos moderados com braços e tronco (ex: datilografia) & 150 \\
Sentado, movimentos moderados com braços e pernas (ex: dirigir) & 150 \\
De pé, trabalho leve, em máquinas ou bancada, principalmente com braços & 180 \\
\hline Trabalho moderado & 175 \\
Sentado, movimentos vigorosos com braços e pernas & 220 \\
De pé, trabalho leve em máquina ou bancada, com alguma movimentação & 300 \\
De pé, trabalho moderado em máquina ou bancada, com alguma movimentação & \\
Em movimento, trabalho moderado de levantar ou empurrar & 440 \\
\hline Trabalho pesado & 550 \\
Trabalho intermitente de levantar, empurrar ou arrastar pesos & \\
Trabalho fatigante &
\end{tabular}

Fonte: NR 15, anexo n`3 (Segurança e Medicina no Trabalho, 2008).

TABELA 3. Limites de tolerância para trabalhos intermitentes com períodos de descanso no próprio local de trabalho em IBUTG $\left({ }^{\circ} \mathrm{C}\right)$. Tolerance limits for intermittent work with rest periods at the workplace in IBUTG $\left({ }^{\circ} \mathrm{C}\right)$.

\begin{tabular}{|c|c|c|c|}
\hline \multirow{2}{*}{$\begin{array}{c}\text { Regime de Trabalho Intermitente com } \\
\text { Descanso no Próprio Local de Trabalho } \\
\text { (por hora) }\end{array}$} & \multicolumn{3}{|c|}{ Tipo de Atividade } \\
\hline & Leve & Moderada & Pesada \\
\hline Trabalho contínuo & até 30,0 & até 26,7 & até 25,0 \\
\hline $\begin{array}{l}45 \text { minutos trabalho } \\
15 \text { minutos descanso }\end{array}$ & 30,1 a 30,6 & 26,8 a 28,0 & 25,1 a 25,9 \\
\hline $\begin{array}{l}30 \text { minutos trabalho } \\
30 \text { minutos descanso }\end{array}$ & 30,7 a 31,4 & 28,1 a 29,4 & 26,0 a 27,9 \\
\hline $\begin{array}{l}15 \text { minutos trabalho } \\
45 \text { minutos descanso }\end{array}$ & 31,5 a 32,2 & 29,5 a 31,1 & 28,0 a 30,0 \\
\hline $\begin{array}{l}\text { Não é permitido o trabalho sem a adoção de } \\
\text { medidas adequadas de controle }\end{array}$ & acima da 32,2 & acima de 31,1 & acima de 30,0 \\
\hline
\end{tabular}

O método OWAS (Ovako Working Posture Analysing System) foi utilizado para a avaliação das posturas adotadas pelos funcionários durante a jornada de trabalho. As posturas foram analisadas a partir de registros fotográficos do indivíduo em situação real de trabalho, ou seja, a cada postura adotada pelo trabalhador para realizar determinada atividade, os registros fotográficos eram efetuados, sem ter uma frequência de captura predefinida. Foram consideradas posturas relacionadas ao tronco, braço, pernas, o uso de força necessária para desempenhar uma função e a fase da atividade, para assim fazer estimativas da proporção do tempo durante o qual as forças são exercidas e posturas assumidas.

Durante a observação, são consideradas as posturas relacionadas aos membros do corpo, sendo atribuídos valores e um código de seis dígitos. O primeiro dígito do código indica a posição das costas; o segundo, a posição dos braços; o terceiro, a das pernas; o quarto indica levantamento 
de carga ou uso de força, e o quinto e sexto, a fase de trabalho (WILSON \& CORLETT, 1995). A combinação das posições das costas, braços, pernas e o uso de força no método OWAS recebeu uma pontuação que foi incluída o sistema de análise Win - OWAS, com o que foi possível categorizar níveis de ação para medidas corretivas.

O método então classificou as posturas em quatro categorias:

$1^{\circ}$ : postura normal que dispensa cuidados.

$2^{\underline{0}}$ : postura deverá ser verificada durante a próxima rotina de trabalho.

$3^{0}$ : postura que deve merecer atenção a curto prazo.

4ํㅜㄹ postura que deve merecer atenção imediata.

A avaliação biomecânica foi realizada com base em registros fotográficos feitos com o trabalhador em diversos ângulos, durante a realização de suas atividades, tomando como referência a mesma frequência de captura que a utilizada pelo método OWAS. As cargas envolvidas foram medidas e usadas como entrada no programa computacional de modelo biomecânico bidimensional desenvolvido pela Universidade de Michigan, Estados Unidos, que avalia a magnitude do risco em função do cálculo dos esforços induzidos no corpo pelas tarefas.

O programa biomecânico bidimensional avalia a possibilidade de lesão no ombro, cotovelo, dorso, coxofemoral, joelho e tornozelo. A análise dos resultados fornecidos por este software permite estabelecer a carga-limite recomendada, que corresponde ao peso que mais de $99 \%$ dos homens e $75 \%$ das mulheres conseguem levantar.

Os dados referentes ao IBUTG foram dispostos em esquemas fatoriais constituídos pela combinação de dois tipos de comedouro (automático e manual) e cinco horários de avaliação (8; 10; $12 ; 14$ e 16h). O delineamento experimental utilizado foi o inteiramente casualizado, com seis repetições (número de granjas com cada tipo de comedouro).

Os fatores ergonômicos referentes à carga física de trabalho, análise postural e biomecânica foram submetidos a uma análise descritiva, por se tratar de fatores que possuem limites máximos e mínimos estabelecidos pela NR (carga física de trabalho) e pelas descrições definidas pelos programas computacionais aos quais foram submetidos (análise postural e biomecânica).

\section{RESULTADOS E DISCUSSÃO}

$\mathrm{Na}$ Tabela 4, apresenta-se a carga de trabalho físico verificado nos galpões equipados com o comedouro automático e manual.

Verifica-se, na Tabela 4, que em todos os galpões onde o sistema de abastecimento de ração era automático, a carga de trabalho físico foi classificada como leve, e o maior valor de CCV encontrado foi de $28 \%$. Nesses galpões, durante a fase de pós-aquecimento, os trabalhadores eram responsáveis por lavar os bebedouros pendulares, revirar toda a cama ou somente parte dela, levar os frangos mortos para a composteira, espalhar palha de café na cama para abrir mais espaço no galpão, além de conferir se todos os equipamentos do galpão estavam funcionando corretamente.

No entanto, nos galpões onde o sistema de alimentação era manual (comedouro tubular), a carga física de trabalho foi classificada como leve a moderadamente pesada. Comparando os dois tipos de sistema de alimentação, pôde-se verificar que o maior valor de CCV foi encontrado em galpões com o comedouro tubular (31\%).

Além do mais, em quatro galpões, verificou-se que a frequência cardíaca dos trabalhadores foram equivalentes e/ou superiores a $100 \mathrm{bpm}$, o que caracteriza a condição de trabalho como moderadamente pesada. Vale ressaltar que, em um funcionário, a FCT foi de $110 \mathrm{bpm}$ para uma jornada de 8 horas de serviço. De acordo com COUTO (2007), o valor da frequência cardíaca não deve ultrapassar $110 \mathrm{bpm}$, pois pode comprometer a saúde do trabalhador, devido à exigência dos sistemas cardíaco e respiratório. 
Nos galpões, onde o sistema de alimentação é manual, os trabalhadores são responsáveis por abastecer os comedouros com o auxílio de baldes de metal (10 e 20 litros) e carrinho próprio para carregar ração.

TABELA 4. Carga física de trabalho exigida nos galpões equipados com comedouro automático e manual. Physical load of work required in sheds equipped with automatic and manual feeder.

\begin{tabular}{|c|c|c|c|c|c|c|c|}
\hline $\begin{array}{l}\text { Galpão com } \\
\text { Comedouro } \\
\text { Automático }\end{array}$ & $\mathrm{CCV}$ & FCT & FCL & FCR & FCM & $\begin{array}{c}\text { Carga Física de } \\
\text { Trabalho }\end{array}$ & $\begin{array}{c}\text { Tempo } \\
\text { de Exposição }\end{array}$ \\
\hline 1 & 13 & 98 & 131 & 84 & 202 & Leve & 5 horas \\
\hline 2 & 16 & 77 & 107 & 56 & 184 & Leve & 5 horas \\
\hline 3 & 15 & 95 & 121 & 79 & 185 & Leve & 5 horas \\
\hline 4 & 20 & 77 & 102 & 50 & 180 & Leve & 5 horas \\
\hline 5 & 28 & 94 & 107 & 62 & 175 & Leve & 5 horas \\
\hline 6 & 24 & 94 & 116 & 60 & 200 & Leve & 5 horas \\
\hline $\begin{array}{c}\text { Galpão com } \\
\text { Comedouro } \\
\text { Tubular }\end{array}$ & $\mathrm{CCV}$ & FCT & FCL & FCR & FCM & $\begin{array}{c}\text { Carga Física de } \\
\text { Trabalho }\end{array}$ & $\begin{array}{c}\text { Tempo } \\
\text { de Exposição }\end{array}$ \\
\hline 1 & 11 & 100 & 131 & 88 & 197 & Mod.Pesado & 8 horas \\
\hline 2 & 18 & 95 & 123 & 72 & 200 & Leve & 8 horas \\
\hline 3 & 16 & 94 & 120 & 76 & 186 & Leve & 8 horas \\
\hline 4 & 28 & 107 & 121 & 70 & 199 & Mod.Pesado & 8 horas \\
\hline 5 & 25 & 110 & 126 & 80 & 197 & Mod.Pesado & 8 horas \\
\hline 6 & 31 & 100 & 111 & 59 & 190 & Mod.Pesado & 8 horas \\
\hline
\end{tabular}

CCV - carga cardiovascular; FCT - frequência cardíaca de trabalho; FCL - frequência cardíaca limite; FCR - frequência cardíaca de repouso; FCM - frequência cardíaca máxima.

Para realizar o abastecimento dos comedouros manuais, os trabalhadores fazem uso de carrinhos que pesam em média $200 \mathrm{~kg}$. No início da fase de pós-aquecimento, é necessário em torno de 30 carrinhos para abastecer os comedouros de um galpão com aproximadamente 24.000 aves (fêmeas).

Outra atividade considerada muito cansativa pela maioria dos trabalhadores é o revolvimento total ou parcial da cama. Na época em que este trabalho foi realizado, a cama constituída de casca de café, estava sendo reutilizada pela segunda vez, e, em alguns casos, até pela terceira vez. Além de estar cada vez mais pesada e tornar o revolvimento mais difícil, ela libera muitos gases. Os relatos de ardência nos olhos e garganta, sensação de resfriamento e mal-estar, foram narrados por $100 \%$ dos trabalhadores.

De acordo com DINTEN et al. (2006), se por um lado o grau de tecnologia adotado permite o emprego de um número menor de trabalhadores e torna o manejo mais fácil e preciso, por outro cria subtarefas e faz com que o bom funcionamento dos equipamentos dependa muito da vigilância dos funcionários, diminuindo constrangimentos físicos, como menor transporte de carga, mas criando alguns constrangimentos psíquicos, como a própria vigilância.

Na Tabela 5, estão apresentados os valores médios de IBUTG para cada horário estudados. De modo geral os maiores valores do índice foram verificados entre 14 e 16 horas. 
TABELA 5. Valores médios de IBUTG em galpões de frangos de corte na fase de crescimento, de acordo com o horário. Mean values of IBUTG in poultry sheds in the growth phase, according to the schedule.

\begin{tabular}{ccccc}
\hline $\begin{array}{c}\text { Galpão com } \\
\text { Comedouro } \\
\text { Automático }\end{array}$ & IBUTG $\left({ }^{\circ} \mathrm{C}\right)$ & $\begin{array}{c}\text { Classificação } \\
\text { de Acordo com } \\
\text { Tabela } 5\end{array}$ & $\begin{array}{c}\text { IBUTG }\left({ }^{\circ} \mathrm{C}\right) \text { de } \\
\text { Acordo com } \\
\text { Tabela } 6\end{array}$ & $\begin{array}{c}\text { Tempo de } \\
\text { Permanência }\end{array}$ \\
\hline $08 \mathrm{~h}$ & $20,4+/-0,8$ & pesado & 25 & 5 horas \\
$10 \mathrm{~h}$ & $21,9+/-0,9$ & pesado & 25 & 5 horas \\
$12 \mathrm{~h}$ & $23,3+/-1,0$ & pesado & 25 & 5 horas \\
$14 \mathrm{~h}$ & $24,3+/-0,7$ & pesado & 25 & 5 horas \\
$16 \mathrm{~h}$ & $24,7+/-1,2$ & pesado & 25 & 5 horas \\
\hline Galpão com & & Classificação & IBUTG $\left({ }^{\circ} \mathrm{C}\right)$ de & Tempo de \\
Comedouro & IBUTG $\left({ }^{\circ} \mathrm{C}\right)$ & de Acordo com & Acordo com & Permanência \\
Tubular & & Tabela 5 & Tabela 6 & 8 horas \\
\hline 08h & $21,3+/-0,4$ & pesado & 25 & 8 horas \\
$10 \mathrm{~h}$ & $22,4+/-1,2$ & pesado & 25 & 8 horas \\
$12 \mathrm{~h}$ & $24,0+/-1,5$ & pesado & 25 & 8 horas \\
$14 \mathrm{~h}$ & $24,5+/-1,1$ & pesado & 25 & 8 horas \\
\hline $16 \mathrm{~h}$ & $24,5+/-0,6$ & pesado & 25 & \\
\hline
\end{tabular}

De modo geral, das 08 até as 16 horas, como esperado, os valores de IBUTG aumentaram. De acordo com a eq.(3), para representar os dados, os maiores aumentos de IBUTG ocorreram nas primeiras horas do dia (Figura 1).

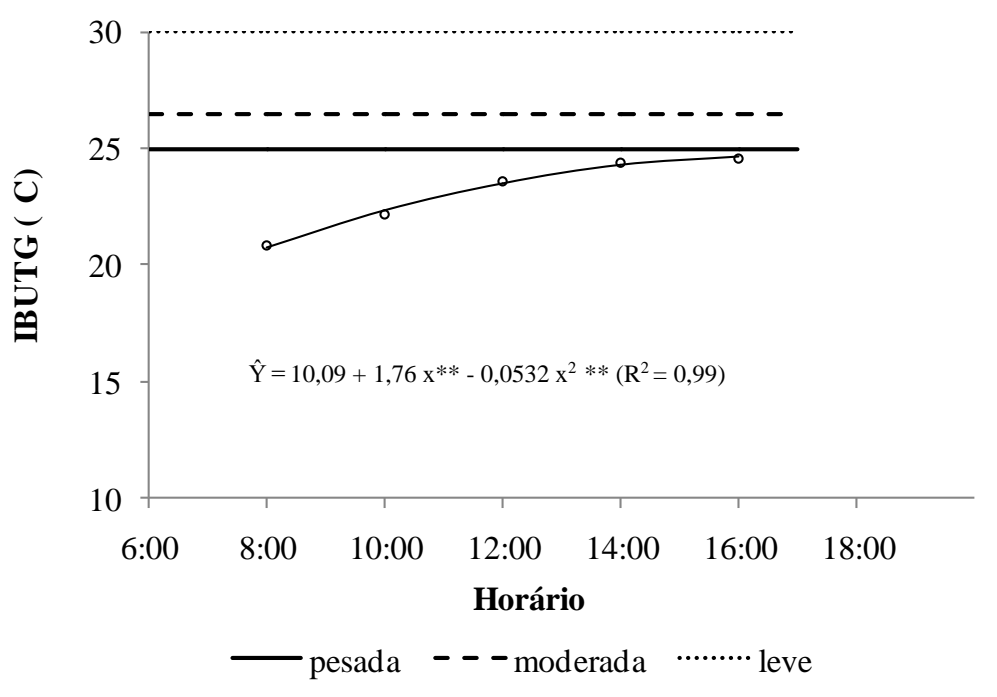

FIGURA 1. Variação do IBUTG em função dos horários estudados, dentro de cada galpão, quando comparado, os sistemas de abastecimento de ração e representação dos valores-limite para essas atividades. Variation of IBUTG as a function of time studied, within each shed when compared with the feed supply systems and representation of the limits for these activities.

Na fase de crescimento das aves, o manejo do galpão consiste em abastecer comedouro, lavar bebedouro e revirar a cama (somente até os 30 dias de idade). Contudo, essas tarefas são realizadas até o final da manhã; sendo assim, a partir das 12 horas, quando as temperaturas começam a ficar mais elevadas, os ventiladores geralmente são acionados, e o funcionário dificilmente se encontra no interior do galpão. 
De acordo com a NR 15, anexo $n^{\circ} 3$ (2008), observa-se na Tabela 5 que todas as atividades realizadas nos galpões, diferenciadas em função do tipo de sistema de alimentação, foram classificadas como pesadas. A jornada de trabalho entre elas varia de 5 horas (galpões com comedouro automático) a 8 horas (galpões com comedouro manual). Sendo assim, pode-se dizer que os trabalhadores atuantes nos galpões onde o sistema de alimentação é manual, estão expostos a maior esforço físico quando comparado com os galpões onde o sistema de alimentação é manual.

No entanto, verifica-se ainda, na Tabela 5, que em todos os galpões estudados os valores de IBUTG estiveram abaixo do limite máximo estabelecido pela Norma, o que permite supor que os tratadores não estão expostos a esforço físico nesses galpões, durante essa época do ano.

Para a realização da avaliação postural, foram analisadas as posturas corporais assumidas pelos funcionários dos galpões, comparando os sistemas de abastecimento de ração.

A postura adotada no manejo do galpão, classificada como categoria 1, e que dispensa maiores cuidados, foi a limpeza do bebedouro, quando o trabalhador utilizava um balde de 50 litros para limpar e retirar a água que ficava em excesso no bebedouro, não precisando curvar-se para lavar o equipamento.

Apesar do peso de $25 \mathrm{~kg}$ do saco de frangos mortos, a atividade foi classificada como categoria 2, em virtude da postura ereta adotada pelo trabalhador durante o carregamento do saco até a composteira. A ocorrência desta categoria requer cuidados ao longo prazo.

As atividades classificadas como categoria 3 foram o revolvimento da cama, com o auxílio do revolvedor de metal, e o enchimento do balde com ração ou casca de café utilizado na composteira. Para essas atividades, a avaliação postural merece atenção a curto prazo.

As atividades que requerem ações corretivas imediatas por terem sido classificadas como categoria 4, foram o revolvimento da cama com o auxílio de enxada e tridente de madeira, abastecimento do comedouro, tração do carrinho de ração e lavagem do bebedouro. Essa classificação foi decorrente da postura incorreta, e em alguns casos, da força adotada pelos funcionários para realizar essas tarefas.

A análise biomecânica evidenciou que o carregamento de sacos de casca de café, o ato de despejar as cascas na composteira e a tração do carrinho de ração expõem os trabalhadores ao risco de lesão no ombro, cotovelo, dorso, coxofemoral, joelho e tornozelo.

O carregamento do saco com casca de café para a composteira acomete o ombro, cotovelo, dorso, joelho e tornozelo.

O carregamento do balde cheio de ração para abastecer os comedouros podem lesionar o ombro, cotovelo e o disco L5/S1 (dorso), enquanto o enchimento do balde com a ração e o abastecimento do comedouro comprometem os ombros e o cotovelo. Durante o recolhimento de frango morto para ser levado para a composteira, observam-se riscos de lesão no cotovelo e, durante a pesagem, o risco é verificado no coxofemoral.

Algumas atividades podem desencadear distúrbio ou patologia no segmento L5/S1da coluna. De acordo com APUD (1989), se a força de compressão for igual ou superior a 3.423 Newton (N), os trabalhadores estão sujeitos a sérios danos no sistema osteomuscular e inclusive a um possível risco de ruptura do disco intervertebral (L5/S1); desta forma, faz-se necessária a redução do tempo de exposição a essa atividade e peso da carga.

Situação de risco foi observada durante a tração do carrinho de ração que pesa em média $200 \mathrm{~kg}$, e a força de compressão atuante no disco L5/S1 é em torno de $7.400 \mathrm{~N}$. Durante o carregamento de saco de casca de café e de saco de frangos mortos para a composteira, além da pesagem de frangos, o peso atribuído a estes materiais implicam uma carga de compressão de $4.140 \mathrm{~N}, 3.320 \mathrm{~N}$ e $1.683 \mathrm{~N}$, respectivamente. Apesar de oferecer risco de distúrbio ou patologia no segmento L5/S1 da coluna, e devido ao esforço que os trabalhadores exerciam para realizar as 
atividades citadas, o uso de pausas era constante devido ao cansaço relatado pelos mesmos; desta forma, o risco de patologia era amenizado e, alguns casos, eliminado.

Em suma, pode-se dizer que trabalhos de conscientização e treinamento dos funcionários é de extrema importância para o desenvolvimento das atividades de forma correta e salutar, isso porque, de acordo com SILVA et al. (2009), os trabalhadores perceberem saúde apenas como ausência de doença e não como algo amplo que envolve educação, moradia, saneamento básico, lazer, condições econômicas, entre outros determinantes, que poderiam tornar-se fatores de conscientização, caso esses trabalhadores tivessem acesso a treinamento e informação.

\section{CONCLUSÕES}

Comparando os dois sistemas de abastecimento de ração, pode-se concluir que, em galpões avícolas equipados com comedouros tubulares, os trabalhadores estão expostos a maiores esforços físicos quando comparado às atividades de manejo desenvolvidas em galpões equipados com comedouros automáticos, estando, porém, abaixo dos valores recomendados pela Norma Regulamentar do Ministério do Trabalho e Emprego.

A temperatura interfere no manejo, tornando a atividade mais exaustiva; desta forma, independentemente do sistema de abastecimento adotado, o manejo realizado durante épocas mais quentes é considerado pesado.

As posturas adotadas na maioria das atividades merecem ações corretivas imediatas. $\mathrm{O}$ manejo nos galpões equipados com comedouro tubular expõe os trabalhadores a risco de lesão no ombro, cotovelo, dorso, coxofemoral, joelho e tornozelo.

Em suma, o manejo em galpões avícolas equipados com comedouro tubular pode ser considerado prejudicial para o tratador, expondo-o a riscos de saúde e lesão no corpo.

\section{AGRADECIMENTOS}

À Fundação de Amparo à Pesquisa do Estado de Minas Gerais (FAPEMIG), à CAPES (Coordenação de Aperfeiçoamento de Pessoal de Nível Superior), ao CNPq (Conselho Nacional de Desenvolvimento Científico e Tecnológico) e à Universidade Federal de Viçosa (UFV).

\section{REFERÊNCIAS}

ALENCAR, M.C.B.; NÄÄS, I.A.; SALGADO, D D’A.; GONTIJO, L. A. Mortalidade de frangos de corte e comportamento humano no trabalho. 2006. Revista Scientia Agricola. v.63, n.6, p. 529533. Disponível em: <http://www.scielo.br/scielo.php?pid=S010390162006000600003\&script=sci_ abstract\&tlng=pt>. Acesso em: 9 jun. 2009.

AMARAL, T. Um panorama da atividade e a proposta para uma política dirigida à cadeia produtiva do setor avícola, escrito por Tarcísio do Amaral, presidente da Avimig. 2007. Cenário da avicultura de Minas Gerais (Exclusivo). Disponível em:

$<$ http://www.aviculturaindustrial.com.br/site/dinamica.asp?id=5122\&tipo_tabela=negocios\&catego ria=mercado_interno $>$. Acesso em: 8 jun. 2007

APUD, E. Guidelines on ergonomic study in forestry. Genebra: ILO, 1989. 241 p.

COUTO, H. A. Ergonomia aplicada ao trabalho: manual: técnico da máquina humana. Belo Horizonte: ERGO Editora, 1996. v.2.

COUTO, H. A. Ergonomia aplicada ao trabalho: conteúdo básico: guia prático. Belo Horizonte: ERGO Editora, 2007.

DINTEN, C.A.M.; ABRAHÃO, R.F.; OLIVEIRA, J.T.A. Work organization and technological resources in broiler production - an ergonomics approach. Revista Scientia Agricola, v.63, n.1, p.46-54, jan./feb. 2006. Disponível em: 
<http://www.scielo.br/scielo.php?script=sci_arttext\&pid=S0103-90162006000100008>. Acesso em: 29 jul. 2010.

DUL, J.; WEERDMEESTER, B. Ergonomics for beginners. A quick reference guide. London: Taylor \& Francis, 1994. 133 p.

MENEGALI, I.; TINÔCO, I.F.F.; BAÊTA, F.C.; CECON, P.R.; GUIMARÃES, M.C.C;

CORDEIRO, M.B. Ambiente térmico e concentração de gases em instalações para frangos de corte no período de aquecimento. Revista Brasileira de Engenharia Agrícola e Ambiental. v.13, p.984990, 2009. Disponível em: <www.scielo.br/pdf/rbeaa/v13s0/v13s0a22.pdf>. Acesso em: 29 jul. 2010

MINETTE, L.J.; PIMENTA, A.S.; FARIA, M.M.; SOUZA, A.P.; SILVA, E.P.; FIEDLER, N.C. Avaliação da carga de trabalho físico e análise biomecânica de trabalhadores da carbonização em fornos tipo "rabo-quente". Revista Árvore, Viçosa-MG, v.31, n.5, p.853-858, 2007. Disponível em: <www.scielo.br/pdf/rarv/v31n5/a09v31n5.pdf>. Acesso em: 27 jul. 2010.

MIRAGLIOTTA, M.Y.; NÄÄS, I.A.; MANZIONE, R.L.; NASCIMENTO, F.F. Spatial analysis of stress conditions inside broiler house under tunnel ventilation. Revista Scientia Agricola, v.63, n.5, p.426-432, Sep./Oct. 2006. Disponível em: <www.scielo.br/pdf/sa/v63n5/31401.pdf>. Acesso em: 29 jul. 2010

NÄÄS, I.A.; MIRAGLIOTTA, M.Y.; BARACHO, M.S.; MOURA, D.J. Ambiência aérea em alojamento de frangos de corte: poeira e gases. Engenharia Agrícola, Jaboticabal, v.27, n.2, p.326335, maio/ago. 2007. Disponível em: <www.scielo.br/pdf/eagri/v27n2/a01v27n2.pdf>. Acesso em: 14 jul. 2010.

SILVA, E.P.; MINETTE, L.J.; SOUZA, A.P.; BAÊTA, F.C.; FERNANDES, H.C.; MAFRA, S.C.T.; VIEIRA, H.A.N.F. Caracterização da saúde de trabalhadores florestais envolvidos na extração de madeira em regiões montanhosas. Revista Árvore, Viçosa-MG, v.33, n.6, p.1.169-1.174, 2009. Disponível em: <http://www.scielo.br/scielo.php?pid=S0100-

67622009000600019\&script=sci_arttext $>$. Acesso em: 14 jul. 2010.

TINOCO, I.F.F. Avicultura industrial: novos conceitos de materiais, concepções e técnicas construtivas disponíveis para galpões avícolas brasileiros. Revista Brasileira de Ciências Avícolas, Campinas, v.3, n.1, 2001. Disponível em: $<\mathrm{http}: / / \mathrm{www}$. scielo.br/scielo.php?script=sci_arttext\&pid= S1516635X2001000100001\&lng=pt\&nrm=iso >. Acesso em: 8 jun. 2007.

WILSON, J.; CORLETT, N. Evaluation of human work: a practical ergonomics methodology. London: Taylor e Francis, 1995. 1.119 p.

VIGODERIS, R.B.; CORDEIRO, M.B.; TINÔCO, I.F.F.; MENEGALI, I.; SOUZA JÚNIOR, J.P.; HOLANDA, M.C.R. Avaliação do uso de ventilação mínima em galpões avícolas e de sua influência no desempenho de aves de corte no período de inverno. Revista Brasileira de Zootecnia, v.39, n.6, p.1.381-1.386, 2010. Disponível em: 〈www.scielo.br/pdf/rbz/v39n6/30.pdf〉. Acesso em: 28 jul. 2010. 